$\xi=-1$

\title{
Effect of personality traits and learning styles towards students' academic achievement in Johor Bahru
}

\author{
Aqeel Khan ${ }^{1 *}$, Leong Pyh Shin ${ }^{1}$, Sanil S Hishan ${ }^{1}$ Mohamed Sharif Mustaffa ${ }^{2}$, Amalia Madihie ${ }^{2}$, Surena Sabil ${ }^{2}$ \\ ${ }^{1}$ University Technology Malaysia (UTM), Skudai, Johor, Malaysia \\ ${ }^{2}$ Faculty of Cognitive Sciences and Human Development, Universiti Malaysia Sarawak \\ *Corresponding author E-mail: draqeelkhan@gmail.com
}

\begin{abstract}
The purpose of this study is to investigate the effect of personality traits and learning styles towards the students' academic achievement in Johor Bahru. A total of 101 students from IPG Kampus Temenggong Ibrahim were chosen to be part of the respondents with the use of simple random sampling. The instrument Big Five Inventory (BFI), Kolb's Learning Style Inventory and The students' academic achievement is measured through the Cumulative Grade Point Average, also known as CGPA. Descriptive statistics, Chi-Square Test, Spearman's Correlation and Multiple Regression was used to anser research questions. The findings revealed that the most common personality traits displayed by the students are Openness and Conscientiousness while the most common learning style displayed by the students is Converger. The research also revealed that there is no significant effect of the combination of both the personality traits and learning style towards the prediction of the academic achievement among school students. The same goes to the difference of personality traits and learning style between male and female students was not significant as well.
\end{abstract}

Keywords: Personality Traits, Academic Achievement, Learning Style

\section{Introduction}

Every individual is unique in terms of his or her personality traits as well as the learning style, hence it is important to found out how the combination of the personality traits and the learning style affect the students' academic performance. Characteristics differences that are stable among the individual that described that particular individual specifically in terms of actions, feelings and perceptions are theorized to be part of personality traits [1]. These characteristics are then further break down into five different aspect of personality namely Extraversion, Agreeableness, Conscientiousness, Neuroticism and Openness to Experience, which being found empirically from the research [2]. These five aspects what formed the whole personality traits. The relation of personality traits with the learning is not unfamiliar as previously Messick [3] did mentioned that the features of learning could be possibly due to the effects of personality traits.

As for the learning style, it will focus on one of the widely used test in educational psychology that can assesses the learning style [4], Kolb's Learning Style Inventory or LSI. According to Kolb [5], it is said that in order for an individual to learn, one must incorporate each of four main learning abilities namely: concrete experience (CE), abstract conceptualization (AC), reflective observation (RO) and active experimentation (AE). Totaling up all the abilities, it can be used to form the learning styles. There are four basic learning style which can be derived from. First of all, the divergent learning style can be distinguished by the specialization of two abilities, $\mathrm{CE}$ and $\mathrm{RO}$ while the converging learning style can be distinguished by the specialization of other two abilities, $\mathrm{AC}$ and $\mathrm{AE}$. On the other hand, specialization of two abilities, $\mathrm{CE}$ and $\mathrm{AE}$, form the assimilating learning style whereas in the accommodating learning style, $\mathrm{CE}$ and $\mathrm{AE}$ are within the specialization of the abilities. It is being proposed by $[6,7,8]$ that learning styles are crucial in determining the students' academic performance, the way how the learning is practiced, interaction in both students and teachers and the choices made in academic field.

Even though there are researches that showed that students' learning styles indeed will affect the academic achievement significantly, it must be noted that those researches only be done in other foreign countries and the findings can be diverse according to the countries where the researches are being carried out. There will not be an end to exploration and development of distinctive learning style while catering to demands of the environment. Therefore, it is imperative that the understanding of learning style of students and its effect on the academic achievement to be grasped by the teachers or educators in the effort to ensure students' success in academic achievement [9].

\section{Research background}

It is summarized that the relationship between personality traits, learning styles and academic achievement are valid and undeniable as it is proven in the previous studies [10]. Through it have demonstrated that how learning styles and personality traits have influenced the academic achievement. Hence it is clear that these factors are relevant to each other. The combination of personality traits and learning styles may affect the outcome of the academic achievement, depending on the combination of both personality traits and learning styles.

However, there are yet to have researches that involved local students with both the effect of personality traits and learning style. There are researches that covered the effect of personality traits and learning style but none of the research used IPG students as their experimental subject. In order to better understand what stu- 